\title{
Fas and FasL gene polymorphisms are not associated with cervical cancer but differ among Black and Mixed-ancestry South Africans Koushik Chatterjee ${ }^{1}$, Malin Engelmark ${ }^{2}$, Ulf Gyllensten ${ }^{2}$, Collet Dandara ${ }^{3}$, Lize van der Merwe ${ }^{4,5}$, Ushma Galal ${ }^{4}$, Margaret Hoffman ${ }^{6}$ and Anna- Lise Williamson*1
}

Address: ${ }^{1}$ Division of Medical Virology and Institute of Infectious Disease and Molecular Medicine (IIDMM), University of Cape Town, Cape Town, Republic of South Africa, ${ }^{2}$ Departments of Genetics and Pathology, Uppsala University, Uppsala, Sweden, ${ }^{3}$ Division of Human Genetics, Faculty of Health Sciences, University of Cape Town, Cape Town, Republic of South Africa, ${ }^{4}$ Biostatistics Unit, Medical Research Council, Cape Town, Republic of South Africa, ${ }^{5}$ Department of Statistics, Faculty of Natural Sciences, University of Western Cape, Bellville, Republic of South Africa and ${ }^{6}$ School of Public Health and Family Medicine, University of Cape Town, Cape Town, Republic of South Africa

Email: Koushik Chatterjee - koushik.chatterjee@uct.ac.za; Malin Engelmark - malin.engelmark@genpat.uu.se;

Ulf Gyllensten - ulf.gyllensten@genpat.uu.se; Collet Dandara - collet.dandara@uct.ac.za; Lize van der Merwe - lize.van.der.merwe@mrc.ac.za; Ushma Galal - ushma.galal@mrc.ac.za; Margaret Hoffman - margaret.hoffman@uct.ac.za; Anna-Lise Williamson* - anna-

lise.williamson@uct.ac.za

* Corresponding author

Published: 26 November 2009

BMC Research Notes 2009, 2:238 doi:10.1186/1756-0500-2-238
Received: 29 September 2009

Accepted: 26 November 2009

This article is available from: http://www.biomedcentral.com/1756-0500/2/238

(c) 2009 Williamson et al; licensee BioMed Central Ltd.

This is an Open Access article distributed under the terms of the Creative Commons Attribution License (http://creativecommons.org/licenses/by/2.0), which permits unrestricted use, distribution, and reproduction in any medium, provided the original work is properly cited.

\begin{abstract}
Background: Cervical cancer is one of the most important cancers in African women. Polymorphisms in the Fas (FasR) and Fas ligand (FasL) genes have been reported to be associated with cervical cancer in certain populations. This study investigated whether these polymorphisms are associated with cervical cancer or human papillomavirus (HPV) infection in South African women.
\end{abstract}

Findings: Participants were 447 women with invasive cervical cancer (I06 black African and 34I women of mixed-ancestry) and 424 healthy women controls, matched by age, (I0I black African and 323 women of mixed-ancestry) and domicile (rural or urban). Two polymorphisms in Fas gene (FasR-I377G/A, FasR-670A/G) and one in FasL gene (FasL844T/C) were genotyped by TaqMan. None of the polymorphisms, or the Fas haplotypes, showed a significant association with cervical cancer. There was also no association with HPV infection in the control group. However, on analysis of the control group, highly significant allele, genotype and haplotype differences were found between the two ethnic groups. There were generally low frequencies of FasR-I377A alleles, FasR-670A alleles and FasL-844C alleles in black women compared to the women of mixedancestry.

Conclusion: This is the first study on the role of Fas and FasL polymorphisms in cervical cancer in African populations. Our results suggest that these SNPs are not associated with cervical cancer in these populations. The allele frequencies of the three SNPs differed markedly between the indigenous African black and mixed-ancestry populations. 


\section{Background}

Cervical cancer is caused by persistent infection with specific types of human papillomavirus (HPV). During their life-time, many women become infected with HPV but most are able to clear the infection and only a small fraction develop cervical cancer. This indicates that additional risk factors play an important role in the development of cervical cancer. These risk factors include host and viral genetic factors as well as environmental and life style factors [1].

One of the most important mechanisms of the human immune system to control viral infection is to induce apoptosis of viral-infected cells [2]. Apoptosis is a highly regulated process of cell suicide and depends on signals from the cell surface death receptor Fas/CD95, which together with Fas ligand (FasL), triggers programmed cell death [3]. In this paper two polymorphisms in Fas (FasR1377G/A, FasR-670A/G) and one in FasL (FasL844T/C) were studied in South African women with cervical cancer compared to controls without cancer of the cervix. The signals produced by the DNA binding of transcription factors SP1 (stimulatory protein 1) and STAT1 (signal transducer and activator of transcription 1) are associated with transcriptional activation and expression of the FasR gene. FasR-1377 and FasR-670 are located in SP1 and STAT1 binding sites, respectively. It has been shown that the FasR-1377A in the FasR promoter considerably reduces SP1 binding compared to $-1377 \mathrm{G}$, resulting in a decrease of Fas gene expression [4,5]. An $A \rightarrow G$ change at Fas- 670 reduces the expression of the FasR, by abolishing the Gamma interferon activation signal binding site which results in decreased activation of induced cell death [4-6]. It has also been shown that the FasL-844C allele is associated with higher basal expression than the $-844 \mathrm{~T}$ allele and that reduced expression of FasL inhibits the apoptotic activity of the FasR-FasL pathway [7].

Six studies in different populations have been published on the association of these SNPs with cervical cancer. One investigated the FasR-670A/G polymorphism in a casecontrol study in the Chinese population and reported an association of the A allele and A/A genotype with higher risk of developing cervical cancer [8]. The same group showed an association of FasR-670A/A with cervical cancer in another case-control study [9] but did not find an association of the FasR-1377G/A or FasL-844T/C polymorphisms with disease severity. Two studies, one a case control study in a Polish group [10] the second an affected sib-pair (ASP) study in a Swedish group [11], did not detect an association with FasR-670A/G. Two case-control studies, one in the Chinese [12] and the other Swedish [13] populations, investigated the FasL-844T/C polymorphism. While the FasL-844C allele and C/C genotype were associated with cervical cancer in the Chinese study, no such effect was found in the Swedish women.
The importance of host genetic susceptibility factors for cervical cancer development has been demonstrated by epidemiological studies. A hereditary component of cervical tumors was detected in twin studies [14] and in a mother-daughter family study [15]. Biological first-degree relatives of women with cervical cancer have an increased risk of developing cancer of the cervix compared to nonbiological relatives of women with cervical cancer [16]. Several studies addressing the association of cervical cancer with Fas and FasL have been published [8-13], but no studies have been performed in African populations. We therefore studied the association of polymorphisms in Fas and FasL with cancer of the cervix in South African women of black and mixed-ancestry origin.

\section{Methods \\ Participants}

Participants were 447 women with invasive cervical cancer ( 106 black African and 341 women of mixed-ancestry) and 424 controls (101 black African and 323 women of mixed-ancestry) without cancer of the cervix recruited from hospitals or clinics in the Western Cape Province, South Africa. The control women were selected to be representative of the population from which the cases were selected, specifically similar to the cases with respect to age, ethnicity and domicile status (urban/rural), so that case-control status would not be associated with either of those. There were 264 (59\%) urban cases and 183 (41\%) rural cases compared to 247 (58\%) urban controls and 177 (42\%) rural controls. The cases and controls formed part of a study to investigate the association of oral contraceptives with cervical cancer $[17,18]$.

\section{Clinical specimens}

Blood was collected from cases and controls, following written informed consent and stored at $-80^{\circ} \mathrm{C}$. The study was approved by the University of Cape Town Research Ethics Committee (REC REF: 075/2009). The subject identifiers were permanently unlinked from the specimens. The HIV infection status was known for $98 \%$ ( $\mathrm{n}=$ $437)$ of the cases and $94 \%(n=398)$ of the controls and $5 \%$ of the cases and $4 \%$ of the controls were positive for HIV infections. 13\% of the controls were positive for HPV by Digene Hybrid Capture II. 14.5\% of the controls in our study had abnormal cervical cytology.

\section{Extraction of genomic DNA}

The genomic DNA was extracted using TotalNucleicAcid Extraction kit for MagNA Pure Compact nucleic acid extractor (Roche Diagnostics, Germany).

\section{Determination of FasR/FasL polymorphisms}

Reactions were conducted in $5 \mu$ l volumes and contained 10 ng DNA, $1.75 \mu$ l PCR MasterMix (Applied Biosystems), $0.087 \mu \mathrm{l}$ TaqMan assay mix (FasR-1377 (rs2234767, assay id, C_12123966_10), FasR-670 (rs1800682, assay id, 
C_9578811_10), FasL844 (rs763110, custom-designed)) (Applied Biosystems) and $1.16 \mu \mathrm{l}$ distilled water. Cycling conditions on the ABI prism 7900 HT (Applied Biosystems) were 2 minutes at $50^{\circ} \mathrm{C}, 10$ minutes at $95^{\circ} \mathrm{C}$, followed by 40 cycles of 15 seconds at $92^{\circ} \mathrm{C}$ and one minute at $60^{\circ} \mathrm{C}$. End point fluorescence was measured immediately after cycling. Alleles were assigned using SDS 2.0 software (Applied Biosystems) [19]. The genotyping was cross-checked by sequencing 4 samples for each polymorphism.

\section{Statistical Analysis}

The genotype distributions were tested for Hardy-Weinberg equilibrium and linkage disequilibrium in cases and controls. Logistic regression was used to test for genotype, allelic and haplotype associations with cervix cancer status as well as baseline characteristics (age, ethnicity and smoking status) and secondary outcomes such as HIV status, abnormal cytology (Pap smear) and high risk HPV according to Hybrid Capture II HPV Test in the control group.

We inferred haplotypes from the two polymorphisms in FasR, and tested their association with cervix cancer status and between ethnicities in the controls.

Statistical analyses were done with $\mathrm{R}$, the freely available environment for graphics and statistics http://www.rproject.org, and R packages dgc-genetics http://wwwgene.cimr.cam.ac.uk/clayton/software/ and haplo.stats http://CRAN.R-project.org/package=haplo.stats. Broadly, haplo.stats uses the expectation maximisation (EM) algorithm, to calculate maximum likelihood estimates of probabilities, of haplotype pairs (one paternal, one maternal) for each subject, as described in Schaid et al. [20].

\section{Results}

The mean age for black cases was 43.8 yrs (SD 9.2) and for mixed-ancestry cases it was 45.9 yrs (SD 8.1). The mean age for black controls was 42.9 yrs (SD 9.0) and for mixedancestry controls it was 45.6 yrs (SD 8.2). No significant differences in age or HIV status were observed between cases and controls.

The observed genotype frequencies of FasR-1377G/A, FasR-670A/G and FasL-844T/C in the controls were all in Hardy-Weinberg equilibrium (FasR-1377: $\mathrm{P}=0.20$, FasR670: $P=0.58$, FasL-844: $P=0.12$ ). The two FasR polymorphisms were in tight linkage disequilibrium (LD) $(\mathrm{P}<$ 0.05), except in the black controls $(P=0.078)$.

Neither the allelic, nor the genotype frequencies showed a significant association (global P-values, 0.55, 0.12 and 0.77 for FasR-1377A, FasR-670A and FasL-844T respectively) with cervical cancer status (Table 1). The haplotype analysis for FasR-1377/-670 also did not reveal any association with cervical cancer in either the African black (global $\mathrm{P}=0.1130$ ) (Black) or the mixed-ancestry (global $\mathrm{P}=0.7043$ ) population (Table 2 ). The frequency of $1377 \mathrm{~A}$ was $12 \%$ in black cases and $9 \%$ in the black controls, $21 \%$ in mixed-ancestry cases and $19 \%$ in mixedancestry controls. $-670 \mathrm{~A}$ was $18 \%$ in black cases and $24 \%$ in black controls, $36 \%$ in mixed-ancestry cases and 35\% in mixed-ancestry controls. $-844 \mathrm{C}$ was $17 \%$ in black cases and $14 \%$ in black controls, $34 \%$ in both mixed-ancestry cases and controls (Table 1).

The association of three SNPs with ethnicity was investigated only in the control group as the controls represent the larger South-African population. In the control group, all three SNPs showed significant allelic and genotype differences (global P-values, 0.004, 0.001, < 0.001 for FasR1377A, FasR-670A and FasL-844T respectively) between ethnic groups (Table 1). The FasR haplotypes (FasR-1377/ -670) also showed a significant difference (global P-value $<0.001$ ) between the two ethnic groups among controls (Table 3). In the control group, both the GA and AG (FasR-1377 and FasR-670) haplotypes were more frequent in the mixed-ancestry group relative to African black group (AG: 19\% compared to 5\%; GA: 35\% compared to 20\%), while the GG haplotype was more common in blacks $(71 \%)$ as compared to the mixed-ancestry group (46\%).

No significant association was found between any of the secondary outcomes (HIV infection, abnormal cytology (Pap smear) and hybrid capture high risk HPV) and any of the three SNPs in the control group, adjusted for ethnicity (results not shown here).

\section{Discussion}

Polymorphisms in the Fas or FasL genes that impair the apoptotic signals have been associated with susceptibility to a number of different cancers [21-27] including cervical cancer [8-13]. We are the first to study the frequency of the FasR-1377G/A, FasR-670A/G and FasL844T/C polymorphisms in an indigenous black African as well as in a mixed-ancestry population and found no association with cancer of the cervix. The tendencies of the odds ratios (ORs) (FasR-1377A/A 1.37, FasR-670A/A 1.17) point towards an increasing susceptible effect and a need for a larger study. Although the result was not statistically significant, there were more cases with FasR-1377A variant compared to controls in both black African (12\% vs. 9\%) and mixed-ancestry (21\% vs. $19 \%)$ women. Our results agree with the lack of association of Fas SNPs with cervical cancer shown by three other reports $[10,11,13]$. The differing results between studies might be due to one or several factors, including the difference in ethnic origin of populations studied and the difference in sample size. The 
Table I: Counts (n), frequencies (\%) and association statistics for genotypes and minor-alleles (FasR-I377G/A, FasR-670A/G, FasL844T/C).

\begin{tabular}{|c|c|c|c|c|c|c|c|c|}
\hline \multirow[b]{2}{*}{ Genotypes } & \multicolumn{2}{|c|}{ Black } & \multicolumn{2}{|c|}{ Mixed-ancestry } & \multicolumn{2}{|c|}{$\begin{array}{c}\text { Genotype-cervical cancer association, } \\
\text { adjusted for ethnicity }\end{array}$} & \multicolumn{2}{|c|}{$\begin{array}{l}\text { Genotype-ethnic association, in } \\
\text { controls only }\end{array}$} \\
\hline & $\begin{array}{l}\text { Cases } \\
\text { n (\%) }\end{array}$ & $\begin{array}{l}\text { Controls } \\
\text { n (\%) }\end{array}$ & $\begin{array}{l}\text { Cases } \\
\text { n (\%) }\end{array}$ & $\begin{array}{l}\text { Controls } \\
\text { n (\%) }\end{array}$ & P-value & OR $(95 \% \mathrm{Cl})$ & P-value & OR (95\% Cl) \\
\hline \multicolumn{9}{|c|}{ FASR-1377 G $\rightarrow$ A } \\
\hline GG & $74(77)$ & $75(83)$ & $186(64)$ & $196(66)$ & - & I & - & I \\
\hline AG & $21(22)$ & $14(16)$ & $87(30)$ & $86(29)$ & 0.428 & $1.14(0.83-1.58)$ & 0.007 & $0.43(0.22-0.77)$ \\
\hline AA & I (I) & I (I) & $17(6)$ & $13(4)$ & 0.391 & $1.37(0.67-2.87)$ & 0.130 & $0.20(0.01-1.04)$ \\
\hline A allele & $23(12)$ & $16(9)$ & $12 \mid(2 \mid)$ & $112(19)$ & 0.275 & $1.15(0.89-1.49)$ & 0.003 & $0.43(0.24-0.72)$ \\
\hline \multicolumn{9}{|c|}{ FASR-670 A $\rightarrow$ G } \\
\hline GG & $67(65)$ & $54(55)$ & 147 (44) & $136(42)$ & - & 1 & - & I \\
\hline AG & $35(34)$ & $43(43)$ & $132(40)$ & $146(45)$ & 0.099 & $0.79(0.59-1.05)$ & 0.207 & $0.74(0.46-1.18)$ \\
\hline $\mathrm{AA}$ & $I(I)$ & $2(2)$ & $53(16)$ & $39(12)$ & 0.492 & $1.17(0.74-1.87)$ & 0.006 & $0.13(0.02-0.44)$ \\
\hline A allele & $37(18)$ & $47(24)$ & $238(36)$ & $224(35)$ & 0.778 & $0.97(0.79-1.19)$ & 0.003 & $0.57(0.39-0.82)$ \\
\hline \multicolumn{9}{|c|}{ FASL -844 T $\rightarrow$ C } \\
\hline TT & $70(68)$ & $74(74)$ & 143 (44) & $139(44)$ & - & 1 & - & I \\
\hline $\mathrm{CT}$ & $31(30)$ & $23(23)$ & 144 (44) & $136(43)$ & 0.515 & I.I (0.82-I.48) & $<0.001$ & $0.32(0.18-0.53)$ \\
\hline $\mathrm{CC}$ & $2(2)$ & $3(3)$ & $40(12)$ & $40(13)$ & 0.929 & $0.98(0.6 \mathrm{I}-\mathrm{I} .57)$ & 0.001 & $0.14(0.03-0.41)$ \\
\hline C allele & $35(17)$ & $29(14)$ & $224(34)$ & $216(34)$ & 0.797 & $1.03(0.83-1.27)$ & $<0.001$ & $0.34(0.22-0.51)$ \\
\hline
\end{tabular}

P-values and OR (95\% confidence intervals) are for test of genotype or additive allelic association with cervix cancer risk, adjusted for ethnicity, and for genotype/additive association with ethnicity in controls. For genotypes, P-values next to genotype names are for joint model, others are for ORs of specific genotype compared to reference genotype, indicated with OR $=1$. ORs for alleles are the odds for an additional copy of that allele. ORs for genotype-ethnicity association (in controls only) are odds of genotype/allele in black compared to odds of genotype/allele in individuals of mixed-ancestry.

Cases $=$ Women with cancer of the cervix, Controls $=$ Women without cancer of the cervix.

presence of another causative mutation in tight LD with any of these three polymorphisms can also not be ruled out.

We observed statistically significant allele frequency differences for all the three Fas SNPs between ethnic groups in the control women. For FasR-1377G/A, the A allele frequency was $9 \%$ in the black Africans and 19\% in women of mixed-ancestry, which were both markedly lower than the frequency in other populations, such as the $43 \%$ and $31 \%$ in Taiwanese and Chinese populations, respectively $[8,12]$. The FasR-670A allele frequency was $24 \%$ in black Africans and $35 \%$ in women of mixed-ancestry. This is again lower than the average of $53 \%$ for populations from Europe, Australasia and Asia $[4,8,10,28,29]$. The fre- quency of the FasL-844C alleles was 14\% in black women and $34 \%$ in women of mixed-ancestry, which are very low compared to the $69 \%$ and $71 \%$ in the Chinese and Swedish populations respectively $[12,13]$. The unusually low frequency of the Fas and FasL alleles in the African population could contribute to a lower power to detect an association in the present study.

The FasR-1377G/A and FasR-670A/G SNPs are in tight LD in our population. Both the AG and GA haplotypes were significantly more frequent in women of mixed-ancestry compared to GG, the most common haplotype, which was observed at a higher frequency in black women (Table $3)$.

Table 2: Inferred frequencies, \%, for FasR-1 377 and FasR 670 haplotypes and odds ratios for risk of cervix cancer.

\begin{tabular}{|c|c|c|c|c|c|c|}
\hline \multirow[b]{2}{*}{ Haplotype } & \multicolumn{3}{|c|}{ Black } & \multicolumn{3}{|c|}{ Mixed-ancestry } \\
\hline & Cases & Controls & OR $(95 \% \mathrm{Cl})$ & Cases & Controls & OR (95\% Cl) \\
\hline GG & 70 & 71 & I & 44 & 46 & I \\
\hline GA & 18 & 20 & $0.8(0.45-1.43)$ & 36 & 35 & $1.08(0.85-1.38)$ \\
\hline AG & 12 & 5 & $2.07(0.87-4.93)$ & 20 & 19 & $1.12(0.83-1.52)$ \\
\hline $\mathrm{AA}$ & 0 & 4 & - & 0 & 0 & - \\
\hline
\end{tabular}

Odds ratios (95\% confidence intervals) are for testing FasR-1377 and FasR-670 haplotype association with risk of cervix cancer versus reference haplotype GG, stratified by ethnicity. Global $P=0.1130$ (Black) and 0.7043 (Mixed ancestry). 
Table 3: Inferred frequencies, \%, for FasR-1 377 and FasR-670 haplotypes and odds ratios for comparing ethnicity in the control group.

\begin{tabular}{cccc}
\hline Haplotype & Black & Mixed-ancestry & OR (95\% CI) \\
\hline GG & 71 & 46 & I \\
GA & 20 & 35 & $0.45(0.31-0.67)$ \\
AG & 5 & 19 & $0.33(0.19-0.58)$ \\
AA & 4 & 0 & -
\end{tabular}

Odds ratios ( $95 \%$ confidence intervals) are odds of being black compared to mixed-ancestry, for FasR-1 377 and FasR 670 haplotypes versus reference haplotype GG, in the control group. Global P-value $<0.001$.

\section{Conclusion}

Our study did not show a significant association of the FasR-1377G/A, FasR-670A/G and FasL-844T/C polymorphisms with cervical cancer. A statistically significant difference was found in the allele and genotypes frequencies of the three SNPs between women of black African and mixed-ancestry in the control population.

\section{Competing interests}

The authors declare that they have no competing interests.

\section{Authors' contributions}

KC participated in planning of the study, performed extraction of DNA, genotyping, analyzing the results and basic statistical analysis. ME helped in genotyping, analysis and interpretation of the results. CD helped in reporting and interpreting of the results. LM and UGA performed advanced statistical analysis and helped with reporting and interpretation of results. $\mathrm{MH}$ coordinated the collection of the biological samples. UGY helped in planning the study and supervised the genotyping part. ALW was responsible for the storage of the biological samples, helped in planning and supervising the study and helped in interpretation of the results. All authors critically read and took part in finalizing the manuscript.

\section{Acknowledgements}

We are grateful to all the patients and controls who participated in this study. We would also like to thank Emma Ivansson for her technical help, Deborah Constant for helping with database handling and a special thanks to Dianne Marais for editing the manuscript. This work is based upon research supported by the South African Research Chairs Initiative of the Department of Science and Technology and National Research Foundation. It was also supported by the NRF South Africa/Sweden Science and Technology Agreement's Fund.

\section{References}

I. Martin CM, Kehoe L, Spillane CO, O'Leary JJ: Gene discovery in cervical cancer : towards diagnostic and therapeutic biomarkers. Mol Diagn Ther 2007, I I:277-290.

2. Dockrell DH: Apoptotic cell death in the pathogenesis of infectious diseases. J Infect 200I, 42:227-234.

3. Zhang J, Xu X, Liu Y: Activation-induced cell death in T cells and autoimmunity. Cell Mol Immunol 2004, I: I 86-192.
4. Huang $Q R$, Morris D, Manolios N: Identification and characterization of polymorphisms in the promoter region of the human Apo-I/Fas (CD95) gene. Mol Immunol I997, 34:577-582.

5. Sibley K, Rollinson S, Allan JM, Smith AG, Law GR, Roddam PL, et al: Functional FAS promoter polymorphisms are associated with increased risk of acute myeloid leukemia. Cancer Res 2003, 63:4327-4330.

6. Kanemitsu S, Ihara K, Saifddin A, Otsuka T, Takeuchi T, Nagayama J, et al.: A functional polymorphism in fas (CD95/APO-I) gene promoter associated with systemic lupus erythematosus. J Rheumatol 2002, 29: I 183-II88.

7. Wu J, Metz C, Xu X, Abe R, Gibson AW, Edberg JC, et al:: A novel polymorphic CAAT/enhancer-binding protein beta element in the FasL gene promoter alters Fas ligand expression: a candidate background gene in African American systemic lupus erythematosus patients. J Immunol 2003, 170:132-138.

8. Lai HC, Sytwu HK, Sun CA, Yu MH, Yu CP, Liu HS, et al:: Single nucleotide polymorphism at Fas promoter is associated with cervical carcinogenesis. Int J Cancer 2003, 103:22I-225.

9. Lai HC, Lin WY, Lin YW, Chang CC, Yu MH, Chen CC, et al:: Genetic polymorphisms of FAS and FASL (CD95/CD95L) genes in cervical carcinogenesis: An analysis of haplotype and gene-gene interaction. Gynecol Oncol 2005, 99: | |3-1 | 8.

10. Dybikowska A, Sliwinski W, Emerich J, Podhajska AJ: Evaluation of Fas gene promoter polymorphism in cervical cancer patients. Int J Mol Med 2004, I 4:475-478.

II. Engelmark MT, Renkema KY, Gyllensten UB: No evidence of the involvement of the Fas -670 promoter polymorphism in cervical cancer in situ. Int / Cancer 2004, I | 2: 1084- 085.

12. Sun T, Zhou Y, Li H, Han X, Shi Y, Wang L, et al.: FASL -844C polymorphism is associated with increased activation-induced T cell death and risk of cervical cancer. J Exp Med 2005, 202:967-974.

13. Ivansson EL, Gustavsson IM, Magnusson J], Steiner LL, Magnusson PK, Erlich HA, et al.: Variants of chemokine receptor 2 and interleukin 4 receptor, but not interleukin 10 or Fas ligand, increase risk of cervical cancer. Int J Cancer 2007, I 21:245 I-2457.

14. Ahlbom A, Lichtenstein P, Malmstrom H, Feychting M, Hemminki K, Pedersen NL: Cancer in twins: genetic and nongenetic familial risk factors. J Natl Cancer Inst 1997, 89:287-293.

15. Hemminki K, Dong C, Vaittinen P: Familial risks in cervical cancer: is there a hereditary component? Int J Cancer 1999, 82:775-781.

16. Magnusson PK, Sparen P, Gyllensten UB: Genetic link to cervical tumours. Nature 1999, 400:29-30.

17. Shapiro S, Rosenberg L, Hoffman M, Kelly JP, Cooper DD, Carrara H, et al.: Risk of invasive cancer of the cervix in relation to the use of injectable progestogen contraceptives and combined estrogen/progestogen oral contraceptives (South Africa). Cancer Causes Control 2003, I 4:485-495.

18. Hoffman M, Cooper D, Carrara H, Rosenberg L, Kelly J, Stander I, et al.: Limited Pap screening associated with reduced risk of cervical cancer in South Africa. Int J Epidemiol 2003, 32:573-577.

19. Zoodsma M, Nolte IM, Schipper M, Oosterom E, van der SG, de Vries EG, et al.: Analysis of the entire HLA region in susceptibility for cervical cancer: a comprehensive study. J Med Genet 2005, 42:e49.

20. Schaid DJ, Rowland CM, Tines DE, Jacobson RM, Poland GA: Score tests for association between traits and haplotypes when linkage phase is ambiguous. Am J Hum Genet 2002, 70:425-434.

21. Davidson WF, Giese T, Fredrickson TN: Spontaneous development of plasmacytoid tumors in mice with defective Fas-Fas ligand interactions. J Exp Med 1998, 187:|825-1838.

22. Peters AM, Kohfink B, Martin H, Griesinger F, Wormann B, Gahr M, et al.: Defective apoptosis due to a point mutation in the death domain of CD95 associated with autoimmune lymphoproliferative syndrome, T-cell lymphoma, and Hodgkin's disease. Exp Hematol 1999, 27:868-874.

23. Lee SH, Shin MS, Park WS, Kim SY, Dong SM, Pi JH, et al:: Alterations of Fas (APO-I/CD95) gene in transitional cell carcinomas of urinary bladder. Cancer Res 1999, 59:3068-3072.

24. Lee SH, Shin MS, Park WS, Kim SY, Kim HS, Han JY, et al.: Alterations of Fas (Apo- I/CD95) gene in non-small cell lung cancer. Oncogene 1999, 18:3754-3760. 
25. Takahashi T, Tanaka M, Brannan Cl, Jenkins NA, Copeland NG, Suda $\mathrm{T}$, et al:: Generalized lymphoproliferative disease in mice, caused by a point mutation in the Fas ligand. Cell 1994, 76:969-976.

26. Sun T, Miao X, Zhang X, Tan W, Xiong P, Lin D: Polymorphisms of death pathway genes FAS and FASL in esophageal squamous-cell carcinoma. J Natl Cancer Inst 2004, 96:1030-1036.

27. Zhang X, Miao X, Sun T, Tan W, Qu S, Xiong P, et al.: Functional polymorphisms in cell death pathway genes FAS and FASL contribute to risk of lung cancer. J Med Genet 2005, 42:479-484.

28. Niino M, Kikuchi S, Fukazawa T, Miyagishi R, Yabe I, Tashiro K: An examination of the Apo-I/Fas promoter Mva I polymorphism in Japanese patients with multiple sclerosis. BMC Neurol 2002, 2:8.

29. Seo JC, Han SW, Yin CS, Koh HK, Kim CH, Kim EH, et al.: Evaluation of a Apo-I/Fas promoter polymorphism in Korean stroke patients. Exp Mol Med 2002, 34:294-298.

Publish with Bio Med Central and every scientist can read your work free of charge

"BioMed Central will be the most significant development for disseminating the results of biomedical research in our lifetime. "

Sir Paul Nurse, Cancer Research UK

Your research papers will be:

- available free of charge to the entire biomedical community

- peer reviewed and published immediately upon acceptance

- cited in PubMed and archived on PubMed Central

- yours - you keep the copyright 